\title{
DIGITALIZATION OF AIRPORT DESIGN \\ AND ARCHITECTURE
}

by

\author{
Lead Author: Naveed Khan \\ Co-Author: Yalda Pashai-Fakhri
}

Bachelor of Life Sciences, McMaster University, Department of Health Sciences, 2008

Bachelor of Architectural Science, Ryerson University, Department of Architectural

Science, 2018

\author{
A thesis \\ presented to Ryerson University \\ in partial fulfillment of the \\ requirements for the degree of \\ Master of Digital Media \\ in the Program of \\ Yeates School of Graduate Studies
}

Toronto, Ontario, Canada, 2019

(C) Naveed Khan 2019 


\section{AUTHOR'S DECLARATION FOR ELECTRONIC SUBMISSION OF A THESIS}

I hereby declare that I am the sole author of this thesis. This is a true copy of the thesis, including any required final revisions, as accepted by my examiners.

I authorize Ryerson University to lend this thesis to other institutions or individuals for the purpose of scholarly research.

I further authorize Ryerson University to reproduce this thesis by photocopying or by other means, in total or in part, at the request of other institutions or individuals for the purpose of scholarly research.

I understand that my dissertation may be made electronically available to the public. 


\title{
Digitalization of Airport Design and Architecture
}

\author{
Master of Digital Media \\ Naveed Khan 2019 \\ Yeates School of Graduate Studies \\ Ryerson University
}

\begin{abstract}
Global adoption of digital technology is greatly informing the redesign of airports, aiming to increase efficiency, hospitality, and experience. Airports are transitioning away from traditional typologies of transit hubs and transforming into destinations that offer everything in one place, from retail to dining to entertainment [1].

By examining the socio-cultural, technological, and design shifts as presented by contemporary airports, the current applications of artificial intelligence, biometrics, and personalization and the impacts of digital technology and architectural design as it relates to the overall user experience and transformation of airport typologies is explored. The ways travelers maximize their time while in transit at airports in order to reduce stress and anxiety related to air travel and how operators can create a more sustainable and adaptable workflows are all considerations and strategies that can empower a partnership between architects, airport operators and the public in the planning and development of airport spaces.
\end{abstract}




\section{Acknowledgements}

I would like to express my sincerest gratitude to my academic supervisors, David M. Hogue, Ph.D. UX Design Lead at Google, and Alex Ferworn Ph.D. director of MDM at Ryerson University, who taught me that humility, honesty, and empathy are just as important, if not more so, than the design and technology concepts we explore. I would also like to thank my second reader, Professor Sumit Bhatia who patiently supported me through my many project pivots.

Special thanks to:

Professor Vincent Hui, as without his unwavering mentorship and guidance, I would not be where I am today.

Ahmed Sagarwala for supporting me on my journey through the program from day one.

My co-author and friend, Yalda, for her tenacity and dedication to our work. 


\section{Dedication}

To the Master of Digital Media 6.0, class of 2018-2019, and to Lissa Quaglia, Ahmed Sagarwala, and Alex Ferworn, the people who made it all happen. 


\section{Contents}

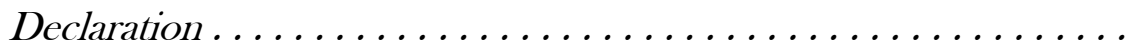

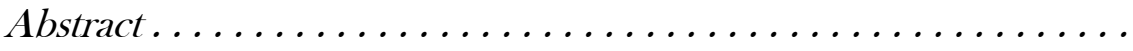

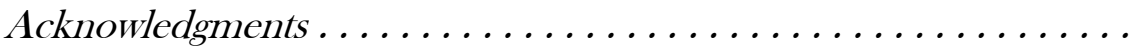

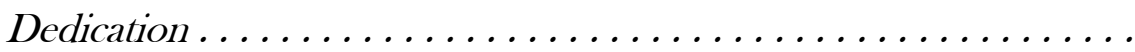

1. Introduction

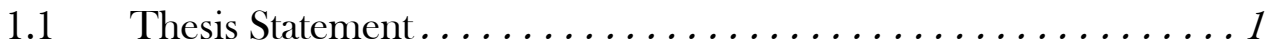

2. Background

2.1 The Current State of Airports .................. 3

2.2 The Current State of Digital Technology in Architecture

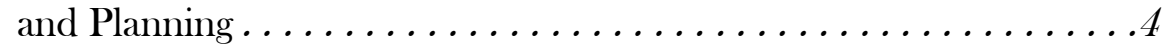

2.3 The Potential Applications of Digital Technologies in Airports . . . . 5

3. Case Studies

3.1 Singapore Changi Airport. ...................

3.2 London Gatwick Airport . . . . . . . . . . . . . . . . 10 


\section{Conclusion}

4.1 The Airport of the Future: Architectural Impacts and

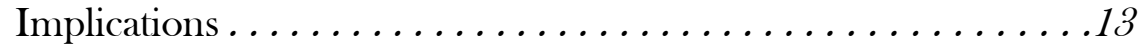

Bibliography. ........................ 15 


\section{Chapter 1}

\section{Introduction}

\subsection{Thesis Statement}

The airport is one of very few intrinsically contemporary building types.

Prior to their advent, there were no precedents from which architects could draw to determine the most effective and efficient way to design such a dynamic, complex, and multifunctional hubs of mass transportation, cultural richness, and architectural pride. Early airports in the first half of the 20" century existed as simple structural sheds that housed the necessities required to maintain and operate aircraft, primarily for military purposes. Following the Second World War, the growth of commercial air travel demanded that airports mature into more robust buildings in order to manage an increasing number of passengers and aircraft. This resulted in a typology of airports which we still see today, one that is separated into three primary programmatic sections for operational organization: a forward-facing terminal which houses arrivals and departures of travelers, a control tower adjacent to the tarmac to manage air traffic, and supporting structures such as hangers, service areas, baggage handling facilities, hotels, and parking garages [2]. 
While this programmatic composition appears to serve the needs of the airport on a theoretical level, it is evident in today's climate of burgeoning global tourism and business that it is failing to meet the anthropomorphic and sociomorphic needs of the public [3]. It is no surprise, then, that airports of the 21 * century are dramatically different entities than their comparatively humble predecessors of the 20" century. In an age of information technology and the move towards the digitalization of nearly every facet of our lives, airport designers and operators are beginning to apply artificial intelligence (AI), biometrics, augmented reality, and big data in order to increase operational efficiency and user experience in these vibrant economic transportation hubs. However, the implementation and testing of such technologies into existing airports is still in its infancy, and so little is known on how these digital technologies will affect not only how we perceive airports socially and culturally, but also how the design and architecture of airports will shift in order to adapt to meet the needs of the 21* century [4].

Drawing on the existing architectural precedents of contemporary airports such as Singapore Changi Airport (Changi), London Gatwick Airport (Gatwick), Dubai International Airport (Dubai) and South Korea Incheon International Airport (Incheon), this paper aims to examine the potential opportunities and constraints of the application of digital technologies and how they can shape the design of airports in the future. 


\section{Chapter 2}

\section{Background}

\subsection{The Current State of Airports}

Traditionally, airports have been designed and utilized as transit nodes for travelers needing to journey by airplane. However, rapidly increasing trends in tourism as a result of globalization and advancement in information and aviation technology are leading architects and aviation planners to reconsider how to better approach airport design in order to maximize their potential as vital economic

generators [5]. As key gateways that connect cities and countries around the world, airports play not only a significant role in moving passengers, but also significantly impact business-related sectors such as tourism, manufacturing, and transport of goods. In fact, the impact of airports on global business is so significant that in 2017, the aviation industry's total global GDP exceeded $\$ 2.7$ trillion USD [3].

In a competitive global climate, airports are focusing on enhancing user experience and design in order to increase their share of air travel and tourism. As a means to rapidly assimilate travelers from around the world, digital technology is being leveraged to facilitate nearly every facet of the airport experience, from safety 
and security, business and operations, and cultural experience. Many airports and airlines have already integrated digital check in and boarding passes as a part of a traveler's experience, and improved the accessibility of media delivered to users in terminals through the addition of mobile technology that aids the visually impaired, blind, or deaf (eg. Toronto Pearson International Airport's Aira app) [6]. Art installations and seasonal programming have also found a digital endpoint, such as Instagram or Facebook, bolstering the digital media presence of airports.

However, success in airport design cannot be solely built and measured on the deployment or integration of new technologies. Airports need to be designed as a flexible and adaptable environments that are able to meet the changing needs of both passengers, staff and operators by leveraging existing and new technologies efficiently [7]. Beyond their localized scope, airports are also bound to global aviation and security regulations, civic and legal obligations to protect their borders, as well as social and humanitarian duties to act as havens during times of war, natural disasters, or other global disturbances [4].

\subsection{The Current State of Digital Technology in Architecture and}

\section{Planning}


Many countries have embraced concepts of big data and smart city infrastructure to accumulate information that can be used to create new opportunities for urban planning and architecture, ultimately improving the lives of citizens and building more robust economies [8]. Cities such as Barcelona and Copenhagen are already implementing public websites where citizens can weigh in on issues related to transportation, culture, and business, giving them agency and access to information that helps to drive productivity and support sustainable improvements to urban infrastructure [9]. In The Netherlands, driverless electric vehicles are being pushed to new limits as a means to reduce carbon footprint and environmental impact while also increasing automation of various transit systems

[10]. In Toronto, Sidewalk Labs is planning and implanting an entire "smart city" that espouses the use of technology to create a more sustainable, eco-friendly and safe urban environments through timber-frame construction, surveillance by AI, and autonomous vehicles [11].

Many of these technologies are now being implemented and tested at airports such as Changi and Gatwick, and data gathered from "staff-less" facilities with passenger interactions being performed via digital devices, biometrics, and robots.

\subsection{The Potential Application of Digital Technologies in Airports}


Almost every airport is currently experiencing some direct or residual effect of the digital evolution. With technology permeating nearly every aspect of our lives, the opportunities present at airports are seemingly unlimited. However, with each application, its potential benefits must be weighed against the ethical and moral implications inherent with current trends in technology and media.

Through the use of big data and AI, airports are moving towards delivering personalized and individual services to millions of passengers. With nearly $90 \%$ of necessary flight data is going directly to a traveler's mobile device, nearly all information shown on typical airport flight information displays is becoming irrelevant, thus creating opportunities to display more engaging content [12]. AI algorithms offer the possibility to deliver the appropriate information to every passenger at the moment they need it, based on location, time before flight, profile, and preference. Whether it is about booking airport services in advance, pushing promotional offers for products, or responding to an emergency or change in travel plans, every traveler will have access to targeted information based upon multiple factors, such as location in the airport, time remaining before flight, purchase history and social network interests. By gathering information on flight histories, shopping habits, service preferences, and social interactions from millions of travelers, airports can enhance their operations to being creating programming that directly reflects the needs and desires of the users [1][2]. 
Digital touchpoints and biometrics are also being applied at airports in North America, Europe, and the Middle East as a means to enhance security screening procedures and reduce time and resources allocated to wayfinding and service or information requests. Self-check in kiosks and automated baggage drop stations are becoming commonplace in a majority of international airports, with some of the largest such as Dubai and Gatwick aiming to replace all staffed check-in stations with automated kiosks by 2022 [13]. AI coupled with video infrastructure could deliver significant enhancements such as biometric face recognition, unusual behavior detection, profiling, or unattended baggage management [5].

AI can also be used in conjunction with AR to increase the capacity of airport staff in their duties, allowing staff to more effectively gather and share data on traveler volume, baggage identification, and flight details, thus increasing overall efficiency across the airport. AR also has the potential to provide travelers with an enhanced user experience at the airport through mobile applications that can be used for navigation, local social connections, retail purchases, or location-based gaming [8].

However, an increasing reliance on digital technologies has its potential hazards. Sensitive and personal data collected on travelers is a valuable target for hackers, and AI systems that malfunction or suffer cyber attacks can cause operational chaos. Cybersecurity measures need to be implemented and tested 
thoroughly prior to deploying new digital technologies in order to mitigate any potential risks [4].

Social and cultural implications of digital technology also need to be addressed, as the moral and ethical constructs of one country or nation may differ greatly from that of another. Allowances and opportunities by digital means at one destination may not be honoured at another, potentially resulting in the disruption of a traveler's itinerary or resulting in tensions between airlines or nations [9]. 


\section{Chapter 3}

\section{Case Studies}

\subsection{Singapore Changi Airport}

Voted as the world's best airport by Skytrax for the past several years, Changi is setting a gold standard as an airport of the future. The architecture of Changi speaks to the intention to design it as a destination from its inception. At Changi's Terminal 4, traveler's experience "Fast and Seamless Travel” (FAST), an end-to-end system that services all passenger touch-points, from check-in and bag drop to immigration and boarding, as a self-service and biometrically enhanced process that provides them with a seamless and intuitive experience [7]. Self-service kiosks are used to print personal boarding passes and bag tags and bags are dropped $t$ an automated bag drop machine after traveler's identity has been verified. At immigration, travelers scan their own passport, boarding pass and fingerprint to facilitate the necessary identity checks. The automated immigration gates also use facial recognition technology to authenticate the passengers' identity [13]. 
With these technologies increasing operational productivity and reducing time wasted in processing, Changi's designers and operators have focused on making the airport a destination rather than just a travel node. Architecturally, the airport aims to dramatically combine two environments-an intense marketplace and a paradise garden-into a new culturally-focused typology that weaves together an experience of being in nature with culture and leisure facilities, asserting the concept of the airport as a vibrant urban center. Within the public realm of Changi, travelers can access vast indoor gardens featuring interactive experiences featuring walking trails, cascading waterfalls, and quiet seating areas, with over 200 different species of flora [2]. Surrounding the gardens is a multi-level retail marketplace on five levels that access the garden via a series of vertical canyons. This combination of natural environment and contemporary ideas of retail along with seamless access

through digital technology have resulted in a steady increase of approximately $4 \%$ in travelers through Changi every year since 2015, with many of them making a stopover at the airport as a point of interest or destination on their international trips [3].

\subsection{London Gatwick Airport}

London Gatwick services over 45 million passengers every year, making it one of the busiest international transit hubs in the world. In order to meet increasing passenger growth, operators invested $\$ 58$ million USD in 2016 to 
introduce digitally enhanced bag checks and biometric security "e-gates", with both applications significantly reducing queuing times by allowing travelers to take charge of their own journey through the airport [13]. Psychologically, this has also improved user satisfaction, as traveler's feel that they are in control of their own journey rather than being corralled by uncaring airport staff.

Gatwick is also preparing to deploy Internet of Things technologies, through which sensors can measure numerous parameters across the airport, such as including waste bin levels, occupancy of check-in desks, or energy and temperature control. Data beacons, that connect with an AR app that provides navigation and information to passengers, are being deployed throughout the airport as a means to accurately track travelers location within the terminal and connect rapidly to the Internet via airport-wide Wi-Fi [7][8].

Gatwick is also transforming the way airport information is communicated by deploying chat bots on existing social media platforms such as Facebook Messenger, Skype, and Instagram. On the operations side, machine learning is being used to enhance security and develop passenger journey mapping, allowing gate staff can communicate with travelers who are running late or not present in the boarding lounge in order to better assess accommodations and flight impacts [12]. 
Gatwick serves as an example of how digital technologies can be integrated into existing architecture in order to enhance the user experience with minimal physical or structural impact. 


\section{Chapter 4}

\section{Conclusions}

\subsection{The Airport of the Future: Architectural Impacts and}

\section{Implications}

It is evident that digital technologies are beginning to play an important role in how airports function, as well as the user experience that they create. The airport of the future will inevitably evolve away from the current typology of airports which

distinctly divides public and traveler space from operations and services, resulting in a more homogenized spatial organization that eliminates the one-way nature of airports [2].

Space typically reserved for processing will become amenity space. Online self check-in and self-serve digital kiosks will minimize the ticketing hall, and biometric security screenings will act more as a two-way portal or a tunnel rather than a centralized point of no return, allowing opportunities for travelers to pass through security in an indoor garden or while shopping at a retailer [15].

On the operations side, the concept of "brick and mortar" aircraft gates, customer service desks, and back-of-house areas will be designed as a flexible and 
adaptable zones, eliminating the need for airlines, retailers, and restaurants to take out long-term leases and construct expensive custom kiosks and counters. Through digital media technologies such as AR or projection mapping, airline branding and airport programming will define such flexible operations spaces on an as-needed basis, changing with the touch of a keypad and allowing airports to rapidly respond to traveler's needs on the fly [7].

Ultimately, this will result in the localized evolution of the airport environment, blurring the boundary between the socio-cultural fabric of the city and the airport terminal. As airlines and airports compete to attract customers and tourists, non-traditional design elements such as indoor gardens, biophilia, amusement parks, digital games, large-scale location-based entertainment, and highly-ranked culinary experiences will all lead to a reduction in stress and anxiety, giving passengers a grounded sense of place, while also increasing revenue for the airport [1]. 


\section{Bibliography}

[1] Airports Council International. (2017). Airport Digital Transformation - White Paper.

[2] Bernstein, F. (2013). Airports of the Near Future. Gensler: Dialogue, 24, 1-3.

[3] International Air Transport Association. Facts \& Figures.

https://www.iata.org/pressroom/facts_figures/Pages/index.aspx

[4] Zaharia, S. E., Pietreanu, C. V. (2018). Challenges in Airport Digital Transformation. Transportation Research Procedia, 35, 90-99.

[5] Odoni, A. \& De Neufville, R. (2013). Airport Systems: Planning, Design, and Management, New York: McGraw-Hill Education.

[6] Rizk, C., Mora-Camino, F., \& Batatia, H. (2018). Optimization of Passenger Screening Operations in Air Terminals. Transportation Research Procedia, 35, 23-34.

[7] Little, A., (2015). Airports 4.0: Impact of Digital Transformation on Airport Economics, Travel and transportation, 3-19.

https://amadeus.com/documents/en/airports/research-report/airports-digital-transformation.pdf

[8] Gaur, A. et al. 2015. Smart City Architecture and its Applications based on IoT. Procedia Computer Science, 52, 1089-1094.

[9] Kummitha, R. K. R. 2018. Entrepreneurial urbanism and technological panacea: Why Smart City planning needs to go beyond corporate visioning? Technological Forecasting \& Social Change, 137, 330-339.

[10] Stadler, R., Brenner, W., Hermann, A. 2018. Autonomous Driving : How the Driverless Revolution will Change the World. Bingley:United Kindgom, Emerald Publishing Limited. 211220 .

[11] Keenan, E. 2019. Sidewalk Labs' Toronto plan is exciting. Let's not kill it prematurely. The Toronto Star (Online). Toronto:Torstar Syndication Services.

[12] Farrell, S. 2019. Biometrics in air transport: no flight of fancy. Biometric Technology Today, 2019(1), 5-7. 
[13] Sanchez del Rio, J., et al. (2016). Automated border control e-gates and facial recognition systems. Computers and Security, 62, 49-72.

[14] Kwon, T. \& Moon, H. (2008). Biometric authentication for border control applications. IEEE Transactions on Knowledge and Data Engineering, 20, 1091-1096.

[15] Siroky, J. \& Hlavsova, P. (2014). Optimizing Process of Check-In and Security Check at Airport Terminals. MATEC Web of Conferences, 4(9), 118-128. 